\title{
Feedback on a feedback loop: The hypothalamic-pituitary-gonadal axis
}

\author{
Craig S. Atwood ${ }^{\mathrm{a}, \mathrm{b}, *}$, Mark A. Smith ${ }^{\mathrm{b}}$ and Richard L. Bowen ${ }^{\mathrm{c}}$ \\ ${ }^{a}$ Section of Geriatrics and Gerontology, Department of Medicine, University of Wisconsin and Geriatric Research, \\ Education and Clinical Center, Veterans Administration Hospital, Madison, WI 53705, USA \\ ${ }^{\mathrm{b}}$ Institute of Pathology, Case Western Reserve University, Cleveland, OH 44106, USA \\ ${ }^{\mathrm{c}}$ Voyager Pharmaceutical Corporation, Raleigh, NC 27615, USA
}

James Geddes, University of Kentucky (Review Editor, JAD) served as the Editor for this article since the Editor-in-Chief, George Perry, had a potential conflict of interest.

Recent evidence indicates that transthyretin (TTR), the major transport protein for thyroxine [1] and retinol binding protein [2], plays important roles in amyloid$\beta$ (A $\beta)$ metabolism. Transthyretin has been demonstrated to bind $\mathrm{A} \beta$ in vitro $[3,4]$ and in vivo $[5,6]$, colocalize in $\mathrm{A} \beta$ plaques and within neurons containing intracellular $\mathrm{A} \beta$ [7], and recent evidence suggests it might act as a transport protein for $\mathrm{A} \beta$. Additionally, $\mathrm{sA} \beta \mathrm{PP}$-driven expression of transthyretin appears to be necessary for protection against $\mathrm{A} \beta$ induced neuronal death [7]. Therefore, the regulation of the expression of TTR may have important consequences for the deposition of $\mathrm{A} \beta$ in the brain.

The findings of Tang and colleagues reported in JAD [8] that $17 \beta$-estradiol increases the gene expression of TTR in ovariectomized mice implicates reproductive hormones in the regulation of amyloid transport and deposition. While the sex steroids are undoubtedly important for brain function, they are controlled by a complex feedback loop that is made up of numerous other hormones including: gonadotropin releasing hormone (GnRH); the gonadotropins- luteinizing hormone

*Corresponding author: Craig S. Atwood, Ph.D., University of Wisconsin-Madison Medical School, Wm S. Middleton Memorial VA Hospital (GRECC 11G), 2500 Overlook Terrace, Madison, WI 53705, USA. Tel.: +1 608256 1901, Ext. 11664; Fax: +1 608280 7291; E-mail: csa@medicine.wisc.edu.
(LH) and follicle stimulating hormone (FSH); inhibins; activins; and follistatin. This therefore adds to the complexity of interpreting these results since the perturbation of serum sex steroids via ovariectomy or sex steroid add-back affects the serum concentrations of all members of the hypothalamic-pituitary-gonadal(HPG) axis [9]. Add-back estrogen after ovariectomy fails to take these other hormones into account and is not synonymous with a physiologically normal HPG axis. Receptors for members of the HPG axis including GnRH, LH and activins are present throughout the body and like estrogen, progesterone and androgen receptors, are particularly localized to the limbic system of the brain. The loss of peripheral sex steroid and inhibin production following menopause and during andropause while leading to decreased signaling via sex steroid receptors also results in marked increases in signaling via GnRH, LH and activin receptors [10]. Given these reciprocal changes in signaling and the fact that GnRH, LH and activins have known functions in the brain, the effects attributed to sex steroids could just as easily be attributed to other hormones of the axis. While the authors mention in their discussion that $\mathrm{LH}$ drives $\mathrm{A} \beta \mathrm{PP}$ processing towards the amyloidogenic pathway in vitro and in vivo [11], they overlook the possibility that TTR expression also might be modulated by other members of the HPG axis following ovariectomy.

That hormones may modulate TTR-induced A $\beta$ deposition as a causatory mechanism for the disease needs 
to be examined in light of the fact that TTR potently regulates mitogensis in neuroblastoma cells, possibly via the binding of thyroid hormones [12], and that cellcycle re-entry has been implicated as a causative mechanism in the disease [13]. Downregulation of TTR expression would therefore increase mitogenesis, and the generation of $\mathrm{A} \beta$ which has been strongly associated with cell cycle re-entry $[14,15]$.

These and other recent observations illustrate the need to examine the entire HPG axis when interpreting results obtained from studies involving menopause/andropause, castration, hormone replacement and modulation of receptor expression and/or signaling. One method in addition to surgical castration that might help shed light on this issue is medical castration with GnRH agonists and antagonists. In this case, as opposed to surgically castrated animals which have minimal sex steroids and elevated LH, medically castrated animals will have minimal serum concentrations of sex steroids and suppressed LH. Studies in animals are underway to confirm the role of these hormones in promoting AD neuropathology, and their use in providing an animal model for the disease. Human clinical trials using the GnRH agonist, leuprolide acetate, to suppress $\mathrm{LH}$ in patients with $\mathrm{AD}$ also are currently underway and should provide further insight into these issues.

\section{Disclosure}

Drs. Atwood and Smith are consultants to, and own stock in, Voyager Pharmaceutical Corporation. Dr. Bowen is co-founder and Chairman of Voyager, which has an ongoing clinical trial on the efficacy of GnRH agonists for the treatment of AD.

\section{References}

[1] J.P. Chanoine and I.E. Braverman, The role of transthyretin in the transport of thyroid hormone to cerebrospinal fluid and brain, Acta Med Austriaca. 19(Suppl 1) (1992), 25-28.

[2] H.L. Monaco, The transthyretin-retinol-binding protein com- plex, Biochim. Biophys. Acta. 1482 (2000), 65-72.

[3] A.L. Schwarzman, L. Gregori, M.P. Vitek, S. Lyubski, W.J. Strittmatter, J.J. Enghilde, R. Bhasin, J. Silverman, K.H. Weisgraber, P.K. Coyle et al., Transthyretin sequesters amyloid beta protein and prevents amyloid formation, Proc. Natl. Acad. Sci. USA 91 (1994), 8368-8372.

[4] V. Askanas, W.K. Engel, J. McFerrin and G. Vattemi, Transthyretin Val122Ile, accumulated Abeta, and inclusionbody myositis aspects in cultured muscle, Neurology 61 (2003), 257-260.

[5] K. Tsuzuki, R. Fukatsu, H. Yamaguchi, M. Tateno, K. Imai, N. Fujii and T. Yamauchi, Transthyretin binds amyloid beta peptides, Abeta1-42 and Abeta1-40 to form complex in the autopsied human kidney-possible role of transthyretin for abeta sequestration, Neurosci. Lett. 281 (2000), 171-174.

[6] E. Carro, J.L. Trejo, T. Gomez-Isla, D. LeRoith and I. TorresAleman, Serum insulin-like growth factor I regulates brain amyloid-beta levels, Nat. Med. 8 (2002), 1390-1397.

[7] T.D. Stein, N.J. Anders, C. DeCarli, S.L. Chan, M.P. Mattson and J.A. Johnson, Neutralization of transthyretin reverses the neuroprotective effects of secreted amyloid precursor protein (APP) in APPSW mice resulting in tau phosphorylation and loss of hippocampal neurons: support for the amyloid hypothesis, J. Neurosci. 24 (2004), 7707-7717.

[8] Y.P. Tang, S.Z. Haslam, S.E. Conrad and C.L. Sisk, Estrogen increases brain expression of the mRNA encoding transthyretin, an amyloid beta scavenger protein, J. Alzheimers Dis. 6 (2004), 413-420.

[9] J. Larson, P.R. Larson, H.M. Kronenberg, S. Melmed and K.S. Polonsky, Williams Textbook of Endocrinology, 10th edition, Saunders, Philadelphia, PA, 2002.

[10] R.L. Bowen and C.S. Atwood, Living and Dying for Sex: A theory of aging based on the modulation of cell cycle signaling by reproductive hormones, Gerontology 50 (2004), 265-290.

[11] R.L. Bowen, G. Verdile, T. Liu, G. Perry, M.A. Smith, R.N. Martins and C.S. Atwood, J. Biol. Chem. 279 (2004), 2053920545.

[12] I. Sakabe, S. Paul, T. Mitsumoto, T. Kadoya and T. Shinozawa, A factor that prevents EDTA-induced cell-growth inhibition: purification of transthyretin from chick embryo brain, Endocr. J. 46 (1999), 375-381.

[13] A.K. Raina, X. Zhu and M.A. Smith, Alzheimer's disease and the cell cycle, Acta Neurobiol. Exp. (Wars) 64 (2004), $107-112$.

[14] Y. Chen, D.L. McPhie, J. Hirschberg and R.L. Neve, The amyloid precursor protein-binding protein APP-BP1 drives the cell cycle through the S-M checkpoint and causes apoptosis in neurons, J. Biol. Chem. 275 (2000), 8929-8935.

[15] D.L. McPhie, R. Coopersmith, A. Hines-Peralta, Y. Chen, K.J. Ivins S.P. Manly, M.R. Kozlowski, K.A. Neve and R.L. Neve, DNA synthesis and neuronal apoptosis caused by familial Alzheimer disease mutants of the amyloid precursor protein are mediated by the p21 activated kinase PAK3, J. Neurosci. 23 (2003), 6914-6927. 